\title{
Individual Health Discount Rate in Patients with Ulcerative Colitis
}

\author{
Akbar K. Waljee, MD, MSc, ${ }^{*}$ Arden M. Morris, MD, MPH, Jennifer F. Waljee, MD, MPH, MSc, ${ }^{+}$ \\ and Peter D.R. Higgins, MD, PhD, MSc*
}

\begin{abstract}
Background: In cost-effectiveness analysis, discount rates are used in calculating the value of future costs and benefits. However, standard discount rates may not accurately describe the decision-making of patients with ulcerative colitis (UC). These patients often choose the long-term risks of immunosuppressive therapy over the short-term risks of colectomy, demonstrating very high discount rates for future health. In this study we aimed to measure the discount rate in UC patients and identify variables associated with the discount rate.
\end{abstract}

Methods: We surveyed patients with UC and patients who were postcolectomy for UC to measure their valuations of UC and colectomy health states. We used Standard Gamble (SG) and TimeTrade-Off (TTO) methods to assess current and future health state valuations and calculated the discount rate.

Results: Participants included 150 subjects with UC and 150 subjects who were postcolectomy for UC. Adjusted discount rates varied widely $(0 \%-100 \%)$, with an overall median rate of $55.0 \%$ (interquartile range [IQR] 20.6-100), which was significantly higher than the standard rate of $5 \%$. Within the normal range of discount rates, patients' expected discount rate increased by $0.80 \%$ for each additional year of age, and female patients had discount rates that averaged $\approx 8 \%$ less than their age-matched counterparts and approached statistical significance.

Additional Supporting Information may be found in the online version of this article.

Received for publication September 2, 2010; Accepted September 5, 2010.

From the *Division of Gastroenterology, Department of Internal Medicine, University of Michigan, Ann Arbor, MI, 'Department of General Surgery, University of Michigan, Ann Arbor, MI.

Supported by the American Society of Colon and Rectal Surgeons Limited Project Grant \#078 A.M.M. Opinions expressed are those of the authors and not the American Society of Colon and Rectal Surgeons.

Reprints: Akbar K. Waljee, MD, MSc, Division of Gastroenterology, Department of Internal Medicine, University of Michigan, 6520 MSRB I, Box 0682, 1150 W Medical Center Dr., Ann Arbor, MI 48109 (e-mail: awaljee@med.umich.edu)

Copyright $\odot 2010$ Crohn’s \& Colitis Foundation of America, Inc.

DOI 10.1002/ibd.21515

Published online 16 November 2010 in Wiley Online Library (wileyonlinelibrary.com).
Conclusions: The accepted discount rate of 5\% grossly underestimates UC patients' preference for long-term over short-term risk. This might explain UC patients' frequent choice of the longterm risks of immunosuppressive medical therapy over the shortterm risks of colectomy.

(Inflamm Bowel Dis 2011;17:1328-1332)

Key Words: ulcerative colitis, discount rates, quality of life, utilities

A pproximately 600,000 people in the United States suffer from ulcerative colitis (UC), requiring frequent colonoscopy and chronic medical therapy. Among these patients, $20 \%-30 \%$ will undergo surgical therapy at some point in their lifetime. ${ }^{1,2}$ Typically, UC follows a waxing and waning course of severity, and acute flares often force patients to make urgent choices between therapies. Patients are frequently required to decide between surgical therapies with short-term risk and immunosuppressive therapies with delayed risk.

To better support patients who face these complex decisions, current investigations are focused on factors that influence patients' assessment of the relative risks of therapies. ${ }^{3,4}$ One important factor in this assessment is the patient's health discount rate. The health discount rate describes the relationship between how patients value short-term costs, risks, and benefits compared with how patients value long-term costs, risks, and benefits. ${ }^{5-7}$ These valuations can have a substantial influence on decision-making preferences.

In decision analytic models for UC, early colectomy is often a dominant strategy, with small short-term risk and large long-term benefits. However, in practice UC patients rarely choose a preemptive colectomy option. The standard approach to discounting in decision analytic models is to discount future health at a rate similar to the discounting of monetary costs, at a rate of $1 \%-8 \%$ per year, with $5 \%$ being the most commonly accepted discount rate. ${ }^{8}$ Although this $5 \%$ discount rate is commonly accepted and used in decision analytic models, experience suggests that it may not accurately predict the health decision-making of UC patients. Standard discount rates suggest that most patients 
have only slightly more aversion to short-term risks than long-term risks. However, empirical evidence suggests that most UC patients worry much more about the short-term risks of surgery than the delayed risks of immunosuppression. If there truly is a significant difference in UC patient discount rates from the standard $5 \%$, this could help explain the discrepancy between the outcomes of cost-effectiveness analyses and the actual behavior of UC patients making their own healthcare decisions.

The purpose of this study to was to estimate the health discount rate in UC patients, and to compare that to the standard 5\% discount rate. Because UC patients often choose to avoid short-term risk (surgery) in favor of longterm risk (immunosuppression), we hypothesized that UC patients' discount rates would be significantly higher than the $5 \%$ discount rate typically used in decision analytic models. To test this hypothesis, we surveyed patients using standardized scenarios to address the following aims: 1) to calculate the discount rate for UC patients; and 2) to identify variables that affect discount rates.

\section{PATIENTS AND METHODS}

This study was a cross-sectional convenience sample of tertiary care patients, including UC patients with intact colons and UC patients who were postcolectomy. Patients were recruited from the general medicine, gastroenterology, and general surgery clinics at the University of Michigan hospital. Postcolectomy patients were recruited from data obtained for the University of Michigan Data Warehouse repository in order to avoid bias towards poor postoperative outcomes. We included any patient age 18 years and older if they had biopsy-proven UC and were able to give informed consent in this study $(n=300)$. We excluded patients who were 1) younger than 18 years of age; 2) unable to provide informed consent; 3 ) employees of the university hospital; 4) students at the university; 5) family members of the study team; or 6) diagnosed with Crohn's disease or indeterminate colitis.

All consents and surveys were completed during a face-to-face visits with the study staff. Patients were offered a $\$ 10$ cash incentive for participating in the study. Surveys included patient demographics, disease history, and medication information. Also included were questions designed to measure utilities by 1) Time-Trade-Off (TTO) at the end of their actuarial expected life; and 2) by immediate Standard Gamble (SG) (Surveys available as supporting material on the website). Patients were informed of their actuarial Remaining Life Expectancy based on age and gender, and the Untraded Years of remaining life was calculated from this. ${ }^{9}$ The TTO and SG surveys were used to assess the utility of the patient's own UC experi- ence. The discount rate was then calculated according to the following formula:

Discount Rate $=100 \times\left[\left(\left[\frac{(1-\mathrm{TTO})}{(1-\mathrm{SG})}\right]^{1 / \text { untraded years }}\right)-1\right]$

This formula was derived from the monetary interest compound rate (where $n=$ number of years of interest): ${ }^{10}$

Future Value $=$ Present Value $\times\left[\left[\frac{(1+\text { Discount Rate })}{100}\right]^{n}\right]$

We solved for the interest rate to determine each individuals' healthcare discount rate. In an individual, future losses are considered discounted (less important) compared to present, immediate losses. Patients generally are more willing to consider future, distant risks than immediate risks, making 1-TTO (future trade-off) larger than 1-SG (risk now), allowing calculation of a compounded discount rate.

\section{Modeling}

The dependent variable in our modeling was the calculated discount rate in an individual subject. The independent variables included the following clinical and demographic factors: age, gender, duration of disease, total steroid use in months, whether or not they had a colectomy, and total number of hospitalizations. Demographic information was compared within each group to detect any differences in the study population using $t$-test and chisquare tests. Discount rates were derived with the calculation above. There was significant skew in the data as well as discount rates that were very low $(\leq 0)$ and very high $(\geq 100)$ outliers for the discount rate. Because the discount rate was not normally distributed, we used median rather than mean discount rates as the summary statistic. In addition, we used parametric tests to compare means ( $t$-test) and nonparametric tests (Wilcoxon Rank Sum) were used to compare medians of the discount rates. In addition, for the purposes of calculating the median, very high $(\geq 100)$ discount rates were adjusted to equal 100 and very low $(\leq 0)$ discount rates were adjusted to 0 , so as to allow for meaningful interpretation of the discount rate. The outliers may have been due to floor and ceiling effects, which we addressed using two-stage modeling when performing the logistic regression. We defined outliers as two dichotomous outcomes, assigning "high" $(\geq 100)$ versus "others" as one dichotomous outcome variable, and "low" $(\leq 0)$ versus "others" as a second dichotomous outcome variable. We used logistic regression to identify predictors of: 1) outliers with high discount rates; and 2) outliers with low discount rates. We then used censored Tobit regression to model the nonoutliers with discount rates $>0$ and $<100 .^{11-13}$ 


\section{TABLE 1. Patient Demographics}

\begin{tabular}{lcc}
\hline & \multicolumn{2}{c}{ Ulcerative Colitis } \\
\cline { 2 - 3 } Characteristics & Intact Colon & Postcolectomy \\
\hline $\mathrm{N}$ & 150 & 150 \\
Mean age in years (range)* & $42.09(18-78)$ & $47.87(18-86)$ \\
Male/female gender & $70 / 80$ & $66 / 84$ \\
White/other* & $127 / 23$ & $143 / 7$ \\
$\begin{array}{l}\text { Mean disease duration } \\
\quad \text { in months }\end{array}$ & $105.5 \pm 106.9$ & $106.4 \pm 106.7$ \\
$\begin{array}{l}\text { Mean duration of steroid } \\
\quad \text { use in months* }\end{array}$ & $12.4 \pm 20.98$ & $20.69 \pm 33.88$ \\
Average number of & & \\
$\quad$ hospitalizations (range)* & $1.42(0-15)$ & $2.97(0-100)$ \\
$* P<0.05$. & & \\
\hline
\end{tabular}

All data preparation, logistic regression, and graphing was performed using Stata 10.1 (StataCorp, College Station, TX) by A.W. and P.D.R.H., and two-sided $P$ values less than 0.05 were considered statistically significant.

\section{RESULTS}

The two patient groups (the UC patients with an intact colon and UC patients who were postcolectomy) were similar with regard to gender, but differed in minor ways with regard to age and ethnicity (Table 1). Patients who had undergone colectomy were significantly more likely to be older and Caucasian. As expected, postcolectomy patients experienced longer use of steroid therapy and higher numbers of total hospitalizations than patients who had not undergone colectomy for UC.

Adjusted median discount rates for the two patient groups were calculated from individual survey responses regarding the patients' actual quality of life (Table 2). UC patients who were postcolectomy tended to have higher discount rates than UC patients who had an intact colon but the differences were not statistically significant. Overall median adjusted discount rate was $55 \%$ (interquartile range [IQR] 20.6-100).

Logistic multivariate analyses were used to predict the outliers with high and low discount rates among patients who

\section{TABLE 2. Adjusted Discount Rates}

\begin{tabular}{lcc}
\hline Ulcerative Colitis & Mean (SD) & Median [IQR] \\
\hline Intact colon $\mathrm{N}=150$ & $56.6 \pm 40.3$ & $47.4[20.4-100.0]$ \\
Postcolectomy $\mathrm{N}=150$ & $61.9 \pm 39.4$ & $68.7[21.4-100.0]$ \\
$P$-value & $P=0.25$ & $P=0.24$ \\
\hline
\end{tabular}

IQR, interquartile range; SD, standard deviation.
TABLE 3a. Logistic Regression to Predict Outliers: Predictors of High Discount Rates

\begin{tabular}{lcccc}
\hline & & & \multicolumn{2}{c}{$\begin{array}{c}95 \% \\
\text { Confidence } \\
\text { Limits }\end{array}$} \\
\cline { 3 - 5 } $\begin{array}{l}\text { Independent } \\
\text { Variable }\end{array}$ & $\begin{array}{c}\text { Odds } \\
\text { Ratio }\end{array}$ & $P$-value & LL & UL \\
\hline Female & 0.30 & $<0.005$ & 0.18 & 0.50 \\
Age & 1.04 & $<0.005$ & 1.02 & 1.05 \\
Hospitalizations & 0.92 & 0.11 & 0.83 & 1.02 \\
\hline
\end{tabular}

TABLE 3b. Logistic Regression to Predict Outliers: Predictors of Low Discount Rates

\begin{tabular}{lcccr}
\hline & & & \multicolumn{2}{c}{$\begin{array}{c}\text { 95\% Confidence } \\
\text { Limits }\end{array}$} \\
\cline { 4 - 5 } $\begin{array}{l}\text { Independent } \\
\text { Variable }\end{array}$ & $\begin{array}{c}\text { Odds } \\
\text { Ratio }\end{array}$ & $P$-value & LL & UL \\
\hline Female & 4.76 & 0.02 & 1.28 & 17.71 \\
Age & 1.02 & 0.26 & 0.99 & 1.05 \\
Hospitalizations & 1.02 & 0.23 & 0.98 & 1.08 \\
\hline
\end{tabular}

completed surveys about their own health state. Table 3a describes the patient factors that predict the outliers with high discount rates $(\geq 100)$. In this model, both older age and male gender were significantly predictive of a high discount rate. Female patients were much less likely than male patients to have very high discount rates (odds ratio $[\mathrm{OR}]=0.30,95 \%$ confidence interval $[\mathrm{CI}]: 0.18-0.50$ ), and older patients were more likely to have very high discount rates $(\mathrm{OR}=1.04$, 95\% CI: $1.02-1.05)$ per year. Table $3 \mathrm{~b}$ shows the results of the logistic regression to identify predictors of outliers with very low discount rates. In this model, female patients were more likely than male patients to have a very low $(\leq 0)$ discount rate $(\mathrm{OR}=4.76,95 \% \mathrm{CI}: 1.28-17.71)$.

We then used censored Tobit regression to model the nonoutliers with discount rates $>0$ and $<100(n=172)$, as shown in Table 4. For each additional year of age, patients' expected discount rate increased by $0.80 \%$. Female patients' discount rates approached statistical significance and averaged $\approx 8 \%$ less than age-matched males. Trends were found for hospitalized patients, who tended to have decreased discount rates and for patients postcolectomy, who tended to have increased discount rates.

\section{DISCUSSION}

In summary, patients with UC demonstrated health discount rates much higher than the standard values used in decision analytic modeling. These findings can indicate 
TABLE 4. Tobit Regression for the Discount Rates

\begin{tabular}{lrrrr}
\hline & & & \multicolumn{2}{c}{$\begin{array}{c}95 \% \\
\text { Confidence } \\
\text { Limits }\end{array}$} \\
\cline { 4 - 6 } $\begin{array}{l}\text { Independent } \\
\text { Variable }\end{array}$ & Coefficient & $P$-value & LL & UL \\
\hline Female & -7.99 & 0.056 & -16.19 & 0.20 \\
Age & 0.80 & 0.00 & 0.53 & 1.07 \\
Steroid use (months) & 0.04 & 0.56 & -0.09 & 0.17 \\
Hospitalizations & -0.40 & 0.10 & -0.88 & 0.08 \\
Colectomy & 6.49 & 0.11 & -1.42 & 14.4 \\
\hline$N=172$ (145 uncensored). & & & & \\
\hline
\end{tabular}

a strong aversion to immediate risks in favor of distant future risks and/or indicate a very low valuation of future health among UC patients. Male gender and older age were predictors of very high discount rates and female gender was the only predictor of very low discount rates. Within the normal range of discount rates, patients' expected discount rate increased by $0.80 \%$ for each additional year of age, and female patients had discount rates that averaged $\approx 8 \%$ less than their age-matched counterparts, and approached statistical significance.

Our data highlight a conflict between clinical experience with UC patients and the decision analysis literature. Generally, published studies use the standard monetary discount rate of $5 \%$ in cost-effectiveness analyses in order to comply with discounted utility theory. Accepted practice in decision analysis suggests that when items such as healthcare and money are exchanged, the same discount rate should be used. ${ }^{714-16}$ However, our current data and data from other disease states ${ }^{17}$ support our hypothesis that patients' individual health discount rates can be much higher than monetary discount rates.

Our primary goal was to calculate health discount rates in UC patients in order to better understand why UC patients often decide against surgery in favor of immunosuppression. If early colectomy is considered a viable strategy with a standard 5\% discount rate, then early colectomy would be the logical cost-effective choice using standard discount rates in UC. However, few patients choose this option. ${ }^{18}$ Our data help to explain why early colectomy is often left out altogether as an option in cost-effectiveness studies. In addition, this study provides an opportunity to identify factors that influence the discount rate in UC.

Within the normal range of discount rates, we found that there was a trend towards females having lower discount rates than males. This suggests that female patients would be more likely to accept the short-term risk of surgery over the long-term risk of ongoing immunosuppres- sion or infertility. This difference might have been driven by fertility issues, which may be a more pressing issue for women than for men. In a sub-analysis, women $<$ age 40 years tended to have a lower discount rate than males. This finding was reversed among women of age $>40$ years, but the difference was not statistically significant (data not shown). This suggests that females with UC may have different discount rates versus males. Decision-making in females could also be influenced by valid differences in how physicians discuss these options with them. For example, physicians might emphasize the risk of infertility in young women considering an ileal-pouch anal anastomosis. ${ }^{19}$ However, in this study we used standardized scenarios in both genders to eliminate physician counseling effects. In contrast, older patients have higher discount rates. These data suggest that older adults are less willing to take short-term surgical risks when their remaining life span is limited.

This study provides a novel insight into the apparently contradictory patient preference for delayed risk in $\mathrm{UC}$, and therefore may serve to enhance patient education about choices in UC therapy. Providers can use our derived UC patient health discount rate to better educate patients about their therapeutic options, and to offer insight into how they may value these options in medical decisionmaking. ${ }^{20}$ Discount rates reflect a patient's relative valuation of short-term versus long-term outcomes. We found (as have many others) that there is a wide distribution of discount rates in individuals, who view short-term and long-term risks quite differently. We believe that it is important to discuss with patients the concept of the discount rate, and explain that some people are more willing to take short-term risks (i.e., surgery) to achieve a good outcome, while others would prefer to take long-term risks (i.e., medication with possible risk of cancer) to achieve a good outcome. Patients can then think about whether they tend to prefer short-term versus long-term outcomes in other aspects of their life, and this can sometimes help them decide which approach they are likely to be happiest with. However, we recognize that the application of discount rates in healthcare is challenging, as health practioners struggle with how to communicate relative risks to patients. ${ }^{21}$

Our study is subject to several limitations. We surveyed a study population from a tertiary care center, who may not be generally representative of UC patients. In addition, some studies have shown that health discount rates may change over time or with aging. ${ }^{22-24}$ These data are supported by our finding that age was a significant predictor of discount rates. Finally, it is possible that postcolectomy patients' responses were subject to recall bias. However, we were reassured that subjects' responses demonstrated remarkable consistency when queried in a variety of ways. 
In spite of these limitations, our study shows that individual health discount rates in UC are significantly higher than the standard discount rates used in decision analytic modeling. These higher discount rates may explain UC patient decision-making in frequently choosing medical over surgical therapy. Including discussion of discount rates in patient decision-making might help patients to better weigh the value of short-term versus long-term risks, and to think about their own individual views of the relative value of short-term versus long-term risk. Presenting patients with multiple concepts to support their healthcare decision-making has been shown to be beneficial in other settings. ${ }^{21,25,26}$ Therefore, we conclude that future studies of informed patient decision-making in UC would benefit from including information on health discount rates.

\section{REFERENCES}

1. Carter MJ, Lobo AJ, Travis SP. Guidelines for the management of inflammatory bowel disease in adults. Gut. 2004;53(suppl 5):V1-16.

2. Ingle SB, Dhillon S, Harmsen WS, et al. Risk factors associated with hospitalization among ulcerative colitis patients from Olmsted County, Minnesota, 1970-2001. (Abstract) UEGW. Paris; 2007.

3. Siegel CA, Levy LC, Mackenzie TA, et al. Patient perceptions of the risks and benefits of infliximab for the treatment of inflammatory bowel disease. Inflamm Bowel Dis. 2008;14:1-6.

4. Man-Son-Hing M, Laupacis A, O'Connor AM, et al. A patient decision aid regarding antithrombotic therapy for stroke prevention in atrial fibrillation: a randomized controlled trial. JAMA. 1999;282:737-743.

5. Olsen JA. On what basis should health be discounted? J Health Econ 1993;12:39-53.

6. Krahn M, Gafni A. Discounting in the economic evaluation of health care interventions. Med Care. 1993;31:403-418.

7. Gold MR. Cost-effectiveness in health and medicine. New York: Oxford University Press; 1996.

8. Smith $\mathrm{DH}$, Gravelle $\mathrm{H}$. The practice of discounting in economic evaluations of healthcare interventions. Int J Technol Assess Health Care. 2001;17:236-243.
9. Arias E. United States life tables. National Vital Statistics Report; 2006:54.

10. Wikipedia. Compound interest. Available at: http://en.wikipedia.org/w/ index.php?title $=$ Compound_interest\&oldid $=373132127$ Accessed 23 July, 2010.

11. Austin PC. Bayesian extensions of the Tobit model for analyzing measures of health status. Med Decis Making. 2002;22:152-162.

12. Austin PC, Escobar M, Kopec JA. The use of the Tobit model for analyzing measures of health status. Qual Life Res. 2000;9:901-910.

13. Austin PC. A comparison of methods for analyzing health-related quality-of-life measures. Value Health. 2002;5:329-337.

14. Weinstein MC, Stason WB. Foundations of cost-effectiveness analysis for health and medical practices. N Engl J Med. 1977;296: 716-721.

15. Loewenstein G, Prelec D. Anomalies in intertemporal choice: evidence and interpretation. $Q J$ Econ. 1992;107:573-597.

16. Fishburn PC, Rubenstein A. Time preferences. Int Econ Rev. 1982;23: 677-694.

17. Chapman GB, Nelson R, Heir D. Familiarity and time preferences: decision making about treatments for migraine headaches and Crohn's disease. J Exp Psychol. 1999;5:17.

18. Provenzale D, Wong JB, Onken JE, et al. Performing a cost-effectiveness analysis: surveillance of patients with ulcerative colitis. Am J Gastroenterol. 1998;93:872-880.

19. Waljee A, Waljee J, Morris AM, et al. Threefold increased risk of infertility: a meta-analysis of infertility after ileal pouch anal anastomosis in ulcerative colitis. Gut. 2006;55:1575-1580.

20. Ortendahl M, Fries JF. Discounting and risk characteristics in clinical decision-making. Med Sci Monit. 2006;12:RA41-45.

21. Edwards A, Elywn G. Understanding risk and lessons for clinical risk communication about treatment preferences. Qual Health Care. 2001; 10:9-13.

22. Cropper ML, Aydede SK, Portney PR. Rates of time preference for saving lives. Am Econ Rev. 1992;82:469-472.

23. Olsen JA. Time preferences for health gains: an empirical investigation. Health Econ. 1993;2:257-265.

24. Cairns JA. Valuing future benefits. Health Econ. 1994;3:221-229.

25. Gyrd-Hansen D, Kristiansen IS, Nexoe J, et al. How do individuals apply risk information when choosing among health care interventions? Risk Anal. 2003;23:697-704.

26. Hembroff LA, Holmes-Rovner M, Willis CE. Treatment decisionmaking and the form of risk communication: results of a factorial study. BMC Med Inform Decis Mak. 2004;16:24. 